\title{
Summary of: Traumatic dental injury and social deprivation in five- year-old children in Scotland 1993-2007
}

\author{
0. Rhouma, ${ }^{* 1}$ A. D. McMahon ${ }^{1}$ and R. Welbury ${ }^{1}$
}

\section{FULL PAPER DETAILS}

1 Glasgow Dental Hospital and School, 378 Sauchiehall Street, Glasgow, G2 3JZ

*Correspondence to: Ousama Rhouma

Email: ousamarhouma@hotmail.com

Tel: +44(141) 2119822

Refereed Paper

Accepted 20 December 2012

DOI: 10.1038/sj.bdj.2013.505

${ }^{\circ}$ British Dental Journal 2013; 214: E26

Objective To describe the pattern and time trends of dental injury and its sociodemographic determinants among fiveyear-old children in Scotland. Design and methods A retrospective analysis of Scottish Health Boards' Dental Epidemiological Programme (SHBDEP) and National Dental Inspection Programme (NDIP) records for the period 1993-2007. Annual incidences were calculated by age, gender, health board and deprivation categories (DEPCAT). Results Out of 68,354 children examined only $405(0.6 \%)$ had suffered dental injury with an overall incidence of 5.9/1000 population. There was a remarkable decrease in incidence over time. Virtually the same rates were recorded for the two genders ( $M: F=1.13: 1.0)$. The incidence varied significantly between health boards' areas $(p<0.001)$; the highest incidence being reported in Dumfries (14.2/1,000 population), which was 11 times greater than that in Ayrshire (1.3/1,000 population). There was no significant association between risk of dental injury and increasing deprivation $(p=0.956)$; in DEPCAT 1 (most affluent) the incidence was 6.4/1,000 population, while in DEPCAT 7 (most deprived) the incidence was 5.7/1,000 population. Conclusion The incidence of dental injury is varied among health boards, though it had significantly decreased since 1993. Gender and deprivation level had no effect on incidence of dental injury.

\section{EDITOR'S SUMMARY}

There is a temptation amongst editors and journals to avoid publishing studies with either negative results or which are works 'in progress'. We are therefore breaking both rules at once with this paper which its authors admit has not managed to show that deprivation level or gender have an effect on incidence of dental injury. They also, perhaps less controversially, state that before conclusions can be drawn with regard to the primary aims of the research they need to reorganise the data collection so that it is representative of the whole population.

So, you may reasonably ask why we have chosen to highlight this paper. It is primarily because of its honesty and because so little other data or information are available on the subject of trauma to the primary dentition, despite the potential longer-term consequences to children who suffer in this way. Additionally, the need for localised data collection and interpretation continues, and arguably strengthens, as we move in England at least to commissioning of health services on a local basis.

Very topically too, the issue of social deprivation is raised here but, interestingly, goes against the trend of other work in failing to positively identify this as a factor associated with trauma to the primary dentition. This is not the case in early childhood caries, for example, a condition also directly affecting the anterior deciduous dentition and creating functional, pathologic and psychological consequences.

As with much research many more questions are raised than answered. Why is there such marked variation between different geographical areas? Is this simply a quirk of data collection? Would a social deprivation gradient exist if the data were collected differently? Why is there an underestimate of the extent of the problem and what is responsible for the decline of the condition in recent years?

Hopefully the authors, or others, will be able to take this starting point and provide some further insight in times to come. Injury of this type to the primary dentition is traumatic it seems not only to young children and their parents but also to researchers.

The full paper can be accessed from the $B D J$ website (www.bdj.co.uk), under 'Research' in the table of contents for Volume 214 issue 10.

Stephen Hancocks Editor-in-Chief

DOI: 10.1038/sj.bdj.2013.506 


\section{TO ACCESS THE BDJ WEBSITE TO READ THE FULL PAPER:}

- BDA Members should go to www.bda.org.

- Click the 'login' button on the right-hand side and enter your BDA login details.

- Once you have logged in click the 'BDJ' tab to transfer to the BDJ website with full access.

IF YOUR LOGIN DETAILS DO NOT WORK:

- Get a password reminder: go to www.bda.org, click the login button on the right-hand side and then click the forgotten password link.

- Use a recommended browser: we recommend Microsoft Internet Explorer or Mozilla Firefox.

- Ensure that the security settings on your browser are set to recommended levels.

IF YOU HAVE NOT YET SIGNED UP TO USE THE BDA WEBSITE:

- Go to www.bda.org/getstarted for information on how to start using the BDA website.
IN BRIEF

- Informs the prevalence of trauma to the primary incisors of five-year-olds in Scotland is low.

- Highlights there was no association between trauma and social deprivation.

- Stresses there is an incomplete collection of data relating to trauma to five-year-olds primary incisors in Scotland and any current data is likely to be an underestimate.

\section{COMMENTARY}

Traumatic dental injuries in children are common and a major cause of distress to both the affected child and the carers. Whilst clinicians know the incidence within the broad population, there are no comparative figures on the prevalence and incidence within the different parts of our communities. There is also a major gap in our knowledge in relating the incidence of traumatic injuries in the younger age group to the socioeconomic status within the community.

This study gives an insight into the incidence and distribution of traumatic dental injuries among fiveyear-old children in Scotland. It was based on the retrospective analysis of records from two epidemiological programmes aimed primarily at capturing caries data in the different regions of Scotland. It is interesting to note that the systems were robust enough at the time to capture additional information of direct relevance to today's NHS economic planning. The result of this study is valuable in planning and delivering public health measures especially in these austere times.

I agree with the authors that the records analysed may not be fully inclusive of all children that may have suffered traumatic injuries, however, it highlights the magnitude of untreated cases of traumatic injuries if the data were based on visual examination.

The authors recognise the limitations of the study as the data analysed were likely to be an underestimation of the actual episodes of traumatic injuries among five-year-olds in Scotland. The study is, however, timely in providing comparative data for traumatic dental injuries among fiveyear-old children across the different health boards in Scotland.

This is a useful beginning and no doubt future studies would provide information on outcomes ranging from patient experiences to clinical outcomes. Commissioning of NHS care and services in England is now a reality. This model may be introduced to other parts of the UK if the English model is successful. Epidemiological systems need to be robust and frontline clinicians should be involved in their design from the outset.

This is a great starting point and further collaborative studies to provide a national outlook is the next logical step.

\section{Dr Ben Cole \\ Newcastle University}

\section{AUTHOR QUESTIONS AND ANSWERS}

1. Why did you undertake this research? Trauma to primary incisors can result in damage to permanent successor incisors resulting in morbidity and a necessity for regular access to dental services thoughout late childhood and early adolescence. This can have a significant impact on a child's quality of life and their journey through adolescence.

Little is known of the true incidence of trauma to primary incisors in Scotland or to what extent this is gender or deprivation related. Some five-year-old data is available from National surveys although this does not exclusively include all types of educational establishments. However, with the current available data we wanted to determine whether trauma was gender or deprivation related. If so this information could help us to plan a further investigation into why this was and how we might reduce this inequality.

\section{What would you like to do next in this} area to follow on from this work?

Existing data relating to trauma to primary incisors in Scotland differ significantly between different health boards but methods of data collection are not exhaustive and are not a true representation of all deprivation categories. Before conclusions can be drawn we need to reorganise our data collection so that it is representative of the whole population. When that has been done then the work can be repeated to get a meaningful answer to the questions of whether trauma to the teeth of five-year-olds is gender or deprivation related. 